Acknowledgements: University of Queensland

Nursing staff at Redcliffe Hospital and Administration officers at Redcliffe \& Northside Rheumatology

Disclosure of Interests: None declared

DOI: 10.1136/annrheumdis-2021-eular.2885

\section{OP0275-PARE THE UNACCEPTABLE DELAY TO DIAGNOSIS IN AXIAL SPONDYLOARTHRITIS; DEVELOPING A CALL TO ACTION FOR A GLOBAL HEALTHCARE CHALLENGE}

W. Gerhart ${ }^{1}$, M. T. Duruöz ${ }^{2}$, J. Lowe ${ }^{3}$, D. Webb $^{4}$, L. Wermskog ${ }^{5}$, J. Davies $^{6}$, R. Howard ${ }^{7}$, M. Mallinson ${ }^{8}$, C. L. Koehn ${ }^{9}{ }^{1}$ Canadian Spondylitis Association, Director, Toronto, Canada; ${ }^{2}$ Marmara University School of Medicine, PMR Department, Istanbul, Turkey; ${ }^{3}$ Axialspondyloarthritis International Federation, Projects, London, United Kingdom; ${ }^{4}$ National Axialspondyloarthritis Society, Director, London, United Kingdom; ${ }^{5}$ Spafo Norge Spondyloartrittforbundet, Director, Oslo, Norway; ${ }^{6}$ Axialspondyloarthritis International Federation, Executive, London, United Kingdom; ${ }^{7}$ Spondylitis Association of America, Executive, Los Angeles, United States of America; ${ }^{8}$ Axialspondyloarthritis International Federation, Volunteering, London, United Kingdom; ${ }^{9}$ Arthritis Consumer Experts, Director, Vancouver, Canada

Background: The current delay to diagnosis from symptom onset represents one of the greatest challenges in axial spondyloarthritis (axSpA). Research shows an average global delay of almost 7 years ${ }^{1}$ - and as long as 15 years in some cases ${ }^{2}$ - during which time the condition can progress considerably and lead to irreversible damage. Data indicates that women wait longer than men for a diagnosis ${ }^{3}$, and there has been very limited progress in reducing the time to axSpA diagnosis. The axSpA diagnosis delay has a hugely detrimental impact on an individual's quality of life. Because the disease frequently has early onset ${ }^{1}$, individuals are left with untreated or incorrectly-treated symptoms at a formative period in their life course, whilst they await their diagnosis.

Objectives: The Axial Spondyloarthritis International Federation (ASIF) set out to coordinate a comprehensive evidence-based global review of the factors influencing the current axSpA diagnosis delay and to produce a definitive report that shines a light on these barriers, as well as providing a resource that can ultimately empower a range of international stakeholders to reduce this delay.

Methods: A full literature review was carried out to identify relevant available global evidence exploring the axSpA diagnosis delay. In autumn 2020 ASIF held two virtual global forum events, involving patients and patient group representatives, researchers, rheumatologists and other healthcare professionals, to methodically explore key diagnosis challenges across different healthcare systems and the opportunities for addressing these. Break-out discussions were held and participants were asked to identify the personal and societal effects of the diagnostic delay; the reasons it occurs; and initiatives to tackle the challenge. Alongside key stakeholder testimonies, best practices from around the world were also identified. 92 stakeholders participated in the events; they represented patients and healthcare professionals from 23 countries across five continents.

Results: The findings from these activities were incorporated within a new 'Delay to Diagnosis' report, which for the first time definitively sets out the lived realities from a global perspective of the axSpA diagnosis delay. The report identified important commonalities across different countries and healthcare systems contributing to the current average global 7-year diagnosis delay, including:

- Poor awareness of axSpA, particularly in primary care services

- Complexities in diagnosing the disease

- Poorly defined referral pathways

- Insufficient patient access to rheumatologists and appropriate diagnostics The report also highlights the significant impact this delay has on individuals and wider society, providing a foundation for future advocacy work. A series of recommendations have also been identified, the implementation of which will help to instigate tangible progress in reducing the current delay.

Conclusion: Despite longstanding challenges, there are now clear opportunities for transforming how axSpA is diagnosed around the world. This message needs to be heard and acted upon urgently by all those involved in the management and delivery of axSpA care. The future programme of work for ASIF's Delay to Diagnosis project will respond to these findings and be centred around supporting axSpA patient associations globally to take this call to action forward throughout 2021 and beyond.

REFERENCES:

[1] Zhao et al; Diagnostic delay in axial spondyloarthritis: a systematic review and meta-analysis; Rheumatology, 2021

[2] Garrido-Cumbrera, M., Poddubnyy, D., Gossec, L. et al. The European Map of Axial Spondyloarthritis: Capturing the Patient Perspective-an Analysis of 2846 Patients Across 13 Countries. Curr Rheumatol Rep 21, 19 (2019)

[3] Jovani et al; Understanding How the Diagnostic Delay of Spondyloarthritis Differs Between Women and Men: A Systematic Review and Metaanalysis; The Journal of Rheumatology December 2016
Disclosure of Interests: Wendy Gerhart Employee of: I was employed by Janssen Canada from 1992 - 2017, Mehmet Tuncay Duruöz: None declared, Jo Lowe Grant/research support from: No financial grants received individu ally. However, my role as Project Manager at ASIF is currently funded partially by UCB Global and partially by Novartis Global, Dale Webb Speakers bureau: Janssen and Novartis, Grant/research support from: Individually, no. But NASS receives grants from AbbVie, Biogen, Eli Lilly, Janssen, Novartis and UCB, Lillann Wermskog Grant/research support from: Individually, no. But Spafo Norge receives a small amount of funding for ongoing projects from Novartis., Jo Davies Grant/research support from: Individually, no. However, ASIF are currently funded by UCB, Lilly, Boehringer Ingelheim, Janssen and Novartis; this funding partially covers staff salaries as well as a range of projects, the content and outputs of which are not influenced by the funders., Richard Howard Shareholder of: AbbVie, Amgen, Bristol-Myers Squibb, GSK, Johnson \& Johnson, Eli Lilly, Merck, Novartis, Pfizer, and Teva. I own $<20$ shares of any one stock and these stocks represent $<4 \%$ of personal investments, Consultant of: Yes, GSK, Novartis - but then donated to Spondylitis Association of America, Grant/research support from: I have not personally received financial grants. SAA has received financial support from AbbVie, Amgen, BI, J\&J, Lilly, Novartis, Pfizer, UCB., Michael Mallinson Consultant of: No. But, for full disclosure: I have received honoraria in the past, for participating in patient advisory board activities, from Abbvie, Novartis, Pfizer and UCB., Cheryl L Koehn Grant/research support from: OUR ORGANIZATION, ARTHRITIS CONSUMER EXPERTS, HAS. I HAVE NOT AS AN INDIVIDUAL. HERE IS OUR PUBLICLY AVAILABLE DISCLOSURE ON ALL ONLINE AND PRINT MATERIALS, PRESENTATIONS, MEETINGS, GOVERNMENT CONSULTATIONS:

https://jointhealth.org/about-principles.cfm?locale=en-CA

Over the past 12 months, ACE received grants-in-aid from: Arthritis Research Canada, Amgen Canada, Canadian Institutes of Health Research, Canadian Rheumatology Association, Eli Lilly Canada, Hoffman-La Roche Canada Ltd. Knowledge Translation Canada, Merck Canada, Novartis Canada, Pfizer Canada, Sandoz Canada, Sanofi Canada, St. Paul's Hospital (Vancouver), UCB Canada, and the University of British Columbia. DOI: 10.1136/annrheumdis-2021-eular.2368

\section{OP0276-PARE CREATING POLITICAL LEVERS TO IMPROVE AXIAL SPONDYLOARTHRITIS CARE}

J. Hamilton ${ }^{1}$, D. Webb ${ }^{2}$, S. Whalley ${ }^{3} .{ }^{1}$ National Axial Spondyloarthritis Society, Head of Policy \& Health Services, London, United Kingdom; ${ }^{2}$ National Axial Spondyloarthritis Society, CEO, London, United Kingdom; ${ }^{3} \mathrm{M} \& \mathrm{~F}$ Health, Health Communications, London, United Kingdom

Background: Research carried out in 2016 by NASS showed that the range and quality of axial spondyloarthritis (axial SpA) services generally offered around the UK were variable ${ }^{1}$. The publication by the regulator, the National Institute for Health and Care Excellence (NICE), of a Guideline for Spondyloarthritis (NG65 in $2017^{2}$ and the corresponding Quality Standard (QS170) in $2018^{3}$, for the first time provided national guidance and standards of services that should be available for people with axial SpA. National oversight of the implementation of these however was missing

Objectives: NASS worked with Parliamentarians to establish the All-Party Parliamentary Group for Axial Spondyloarthritis in January 2019. We gave it a very specific objective - to oversee the implementation of NH65 and QS170. The group seeks to improve axial SpA services in England whilst raising awareness of the condition at a parliamentary level, working closely with NASS.

Methods: The group is a unique forum in the UK, bringing together patients, clinicians, researchers, policy makers, national bodies and parliamentarians. The group has met five times covering a range of topics including the delay to diagnosis, the uptake of NG65 and hydrotherapy.

In 2019 the group carried out a national inquiry into the standards of axial SpA services in the UK, developing a ten-question quality framework, based largely on the NICE Guideline recommendations and Quality Standard. In July 2020 a meeting was convened to discuss the impact of COVID-19 on axial SpA services. The meeting presented research carried out by NASS and M\&F Health with patients and clinicians respectively.

Results: The results of the national inquiry for England were published in January $2020^{4}$. The inquiry found that large discrepancies remain in the provision of axial SpA services. Only $21 \%$ of local commissioning bodies have an inflammatory back pain pathway, and less than half of NHS providers have a specialist axial SpA clinic.

The results of COVID survey shows significant impacts on the health of axial SpA patients and on the availability and modality of rheumatology services. The APPG later published a report with a set of recommendations ${ }^{5}$, creating minimum service specifications for axial SpA services during crisis periods such as the recent pandemic, as well as service recovery. Comment on this research was also published in The Lancet Rheumatology ${ }^{6}$. 